\title{
EFEITOS DE ADITIVOS NA OBTENÇÃO DE IOGURTE EM PÓ POR MEIO DE SECAGEM POR ATOMIZAÇÃO EM ESCALA PILOTO
}

\author{
E.P.D.R. TRIBOLI ${ }^{1}$, G. MAURIC ${ }^{1}$, S.I. ABBAS ${ }^{1}$, M. de L. BRANCO ${ }^{1}$ e J.A.W. GUT ${ }^{2}$ \\ ${ }^{1}$ Instituto Mauá de Tecnologia, Engenharia Química e de Alimentos \\ ${ }^{2}$ Universidade de São Paulo, Departamento de Engenharia Química \\ E-mail para contato: jorgewgut@usp.br
}

\begin{abstract}
RESUMO - O iogurte é o alimento industrializado que mais desperta interesse do consumidor brasileiro e em forma de pó pode ter seu uso diversificado. A secagem de iogurte por atomização é difícil, pois o produto apresenta a tendência de aderir na parede da câmara de secagem. Este estudo aborda o efeito de aditivos maltodextrinas (DE 05, DE 10, EMCAP), goma acácia, leite em pó desnatado e sílica pirogênica (Aerosil 200) — misturados em iogurte natural semidesnatado batido, na proporção de 1:1 em relação ao teor de matéria seca, exceto a sílica pirogênica $(0,23: 1)$, para elevar a temperatura de transição vítrea da mistura. Lotes de $10 \mathrm{~kg}$ foram secos em um atomizador de disco rotativo (26000 rpm) com auxílio de ar aquecido $\left(160^{\circ} \mathrm{C}\right.$ e depressão de $\left.140 \mathrm{mmH}_{2} \mathrm{O}\right)$. As vazões de alimentação foram ajustadas para a capacidade máxima de produção para cada caso. A recuperação de produto em material seco (MS), retenção de MS na parede, perda de MS no equipamento (\%) e a cor do pó (CIE L*a*b*) indicaram que os melhores resultados foram obtidos com a sílica pirogênica em concentrações entre 2 e $4 \%$, produzindo um pó de livre escoamento e com uma boa homogeneidade para a distribuição de partículas do produto.
\end{abstract}

\section{INTRODUÇÃO}

Os iogurtes apresentam-se como os produtos alimentícios industrializados que mais despertam o interesse do consumidor brasileiro (FIESP-ITAL, 2010). Com oportunidades de mercado, não apenas pelo iogurte, mas também por seus derivados, a indústria busca alternativas que sejam competitivas e capazes de oferecer produtos de boa qualidade. O iogurte em pó, como os produtos desidratados em geral, oferece a conveniência de facilidade de manuseio e redução de custos com transporte e armazenagem em temperatura ambiente.

O maior obstáculo encontrado em estudos anteriores referentes à secagem de iogurte por atomização é o fato de o material processado ficar retido na parede da câmara de secagem (Kumar e Misrha, 2004), e que, nos melhores casos, chega a cerca de 20 a $30 \%$ (Triboli e Gut, 2013), ocasionando perda de material, paradas regulares para limpeza e perda de qualidade do produto final (escurecimento por causa de maior exposição à temperatura elevada). Provavelmente, isso é devido à temperatura de transição vítrea da matriz do iogurte que pode estar sendo ultrapassada durante o processo de secagem (Meste et al., 2002). Levando em consideração esta hipótese, aditivos que possuam temperatura de transição vítrea elevada 
podem ser adicionados ao iogurte com o objetivo de diminuir sua condição de gomosidade. Outros aditivos como leite em pó desnatado e goma acácia também são estudados, uma vez que a literatura cita seus usos como auxiliares de secagem em derivados lácteos (Fu e Chen, 2011; Peighambardoust et al., 2011).

Este trabalho visa a melhoria do processo de secagem de iogurte com auxílio de aditivos para aumentar a recuperação do material seco, diminuir a quantidade de material aderido na câmara de secagem e obter uma diferença mínima de cor do produto em relação ao padrão.

\section{REVISÃO DA LITERATURA}

Sabe-se que o processo de secagem do iogurte por atomização causa perda das características nutricionais, sensoriais e reológicas do produto. Porém, o uso de estabilizantes durante o processo pode melhorar essas características (Kumar e Misrha, 2004). O uso de aditivos aumenta a sobrevivência dos microrganismos, favorece a retenção do acetaldeído e ainda permite uma melhor solubilidade e dispersão do iogurte em pó (Kearney et al., 2009). A questão reside em aspectos físico-químicos do material a ser seco e, em especial, sua temperatura de transição vítrea. Esse aspecto tecnológico pode ser parcialmente contornado com a adição de materiais que modifiquem a temperatura de transição vítrea do produto levado a secar, tais como maltodextrinas (Meste et al., 2002).

A aderência de material à parede da câmara é umas das principais causas de perda de produto durante o processo de secagem (Woo et al., 2007). A presença de gotículas maiores no secador por atomização pode fazer com que estas gotas ou aglomerados de partículas cheguem à parede da câmara antes que o processo de secagem esteja completo, resultando na aderência e formação de depósitos. A aglomeração do produto, além de formar torrões (caking) e diminuir a fluidez do pó durante seu escoamento, pode reduzir a capacidade de reidratação e dispersibilidade, favorecer a oxidação de lipídios, gerar perdas sensoriais e de vida de prateleira e, por fim, reduzir o rendimento do processo. É senso comum que um produto com aglomerados é considerado de baixa qualidade, não sendo atrativo aos consumidores (Barbosa-Cánovas et al., 2005).

Diversos estudos foram realizados (Meste et al., 2002; Langrish et al. 2007; Quek et al., 2007; Goula e Adamopoulos, 2008; Turchiuli et al., 2011) no sentido de se obter uma redução na pegajosidade do produto com a utilização de aditivos de secagem para minimizar o depósito na parede da câmara de atomização. Muitos desses aditivos possuem alto peso molecular e alta temperatura de transição vítrea. Os aditivos utilizados para diminuir o processo de deposição reduzem as forças de coesão e adesão do produto a ser seco (Langrish, Chan e Kota, 2007). É comum em alimentos que contém ácido láctico $\left(T_{g}=-60{ }^{\circ} \mathrm{C}\right)$ a formação de depósitos na parede do atomizador, prejudicando o rendimento da operação (Koc et al., 2010).

Em materiais que contém carboidratos, durante o processo de secagem rápida, ocorre o fenômeno de vitrificação, no qual se formam massas de material que funcionam como pontes líquidas ou mesmo sólidas entre partículas. A sílica pirogênica é um material hidrofílico que absorve a película de água existente sobre a superfície dessas massas, quebrando as pontes de líquido e evitando o crescimento de pontes sólidas. Além disso, atua como barreira física de material inerte, aumentando a distância entre as partículas e reduzindo as forças de atração entre elas, favorecendo a fluidez do pó. A sílica pirogênica tem grande aplicação na área 
farmacêutica, sendo o aditivo mais utilizado com extratos vegetais na secagem por atomização (Pereira e Petrovick, 2010). Portanto, com essas propriedades, esse material tem potencial utilização como agente auxiliar de secagem para o iogurte.

\section{MATERIAL E MÉTODOS}

\subsection{Iogurte, Aditivos e Equipamento de Secagem}

Foi utilizado iogurte natural semidesnatado marca Fazenda Bela Vista (Tadiratiba, SP). Os aditivos empregados foram: Maltodextrina DE 05 ( $T_{g}$ ca. $200{ }^{\circ} \mathrm{C}$, Tate \& Lyle), Maltodextrina DE $10\left(T_{g}\right.$ ca. $160{ }^{\circ} \mathrm{C}$, Tate \& Lyle), EMCAP (maltodextrina de estrutura ramificada, Cargill), Goma Acácia (Nexira), Leite em pó desnatado Molico $\left(T_{g}\right.$ ca. $90{ }^{\circ} \mathrm{C}$, Nestlé) e sílica pirogênica Aerosil 200 ( $T_{g}$ ca. $1200{ }^{\circ} \mathrm{C}$, Evonik). A mistura e homogeneização do iogurte com o aditivo foi feita em um Ultra-Turrax T-50 (IKA-Werke, Alemanha). Especificamente no caso do Aerosil, a mistura foi feita em batedeira de 20 L (Perfecta, Brasil). Como houve formação de espuma, foram utilizados os antiespumantes Polissorbato 80 (Pantec) ou Xiameter AFE-1520 (Dow Corning). Os ensaios de secagem de lotes com cerca de $10 \mathrm{~kg}$ de produto foram realizados em secador por atomização com disco rotativo SD-05 (Tecnape, Brasil), modelo com capacidade nominal de evaporação de água de $5 \mathrm{~L} / \mathrm{h}$.

\subsection{Planejamento Experimental}

O estudo foi dividido em duas etapas. Na primeira, o objetivo foi o de se verificar dentre seis aditivos estudados, quais os mais promissores no sentido de reduzir o problema de aderência na câmara de secagem. Na segunda, uma vez definidos os aditivos, estudar a influência de suas concentrações no processo de secagem e nas características do produto. Nesse sentido, para não aumentar desnecessariamente o número de ensaios, não foram feitas repetições.

Testes exploratórios com maltodextrinas em concentrações citadas na literatura ( $\mathrm{Fu}$ e Chen, 2011) produziram nenhum ou pouco efeito observável. Dessa forma optou-se por utilizar uma quantidade de aditivo equivalente ao teor de material seco do iogurte na primeira etapa, ou seja, uma proporção de 1:1, equivalente a uma concentração de 12,7 a 12,8\% em relação à massa de iogurte utilizada no processamento, exceto para o caso do Aerosil, que transformouse numa pasta não bombeável para concentrações superiores a 3\%, sendo essa concentração equivalente a uma proporção de aditivo de 0,23:1 de material seco. A adição de Aerosil nas concentrações de 4 e 5\% exigiu diluição com água até uma condição bombeável.

As condições de processo fixas para todos os ensaios da primeira etapa foram: velocidade

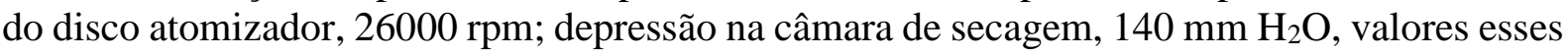
os máximos conseguidos no equipamento; temperatura de entrada do ar na câmara de secagem, $160{ }^{\circ} \mathrm{C}$. Para a vazão de alimentação, buscou-se a capacidade máxima de produção possível para cada aditivo, uma vez que vazões elevadas contribuem para uma cor adequada para o produto (Triboli e Gut, 2013), o que foi determinado por meio de tentativas. Com as maltodextrinas DE 5 e DE 10 foi possível operar em $100 \%$ da capacidade da bomba $(17,5 \mathrm{~kg} / \mathrm{h})$, com iogurte sem aditivos, leite em pó desnatado e Aerosil se trabalhou com 50\% da capacidade, com EMCAP, $40 \%$ e com goma acácia, $35 \%$. 


\subsection{Análise do Produto Seco}

As análises de distribuição do tamanho de partículas foram realizadas pela técnica de difração a laser (Low Angle Laser Light Scattering) no equipamento Mastersizer 2000 (Malvern, UK), utilizando-se álcool isopropílico como agente dispersante. Uma das informações analisadas foi o diâmetro médio de Sauter, que é definido pela razão entre o volume total pela área superficial total das partículas e representa o diâmetro que tem a mesma relação entre volume e superfície para toda a distribuição (Filková et al., 2006). Outra variável explorada foi o span, que caracteriza a largura ou amplitude da dispersão dos diâmetros das partículas.

Com auxílio de um espectrofotômetro ColorQuest XE (Hunter Lab, EUA), foram feitas as medidas dos valores de $L^{*}, a^{*} \mathrm{e} b^{*}$, referentes ao sistema de cores CIELAB, sob o iluminante D65 e com ângulo de observação de $10^{\circ}$, com refletância-especular incluída (RSIN). Para as medidas, foi utilizada uma única cubeta de quartzo de $20 \mathrm{~mm}$. O pó foi compactado com leve pressão. As leituras foram realizadas em quadruplicata, duas para cada face da cubeta, na temperatura ambiente de $24^{\circ} \mathrm{C}$. A análise de diferença de cor $\Delta E^{*}$ foi feita comparando-se os valores obtidos com um padrão de cor. O padrão de cor escolhido foi o do leite em pó desnatado da marca Molico (Nestlé, Brasil), pois este produto desnatado, ao ser reconstituído, apresenta coloração próxima daquela apresentada pelo iogurte fresco.

As análises microscópicas das amostras de iogurte puro e com 2 e $3 \%$ de Aerosil foram realizadas em microscópio eletrônico de varredura (MEV) Quanta 600 FEG (FEI, EUA) equipado com espectrômetro de raios X por dispersão de energia (EDS) Quantax 400 (tecnologia SDD - Silicon Drift Detector) e software Sprit (Bruke, EUA). A rotina de trabalho estipulada compreendeu a coleta de imagens de elétrons secundários. As amostras foram distribuídas em fita dupla face de carbono, metalizadas com platina e fixadas em suporte próprio para MEV.

\subsection{Balanço de Massa}

O balanço de massa para o processo de secagem foi feito com base na seguinte abordagem: o material seco (MS) alimentado é retirado como produto da câmara de secagem e do ciclone. Ao final do processo, o material que ficou aderido na parede da câmara foi removido por um processo de limpeza por escovação. A diferença entre o material seco alimentado e o que saiu do equipamento constitui-se de material perdido.

\section{RESULTADOS E DISCUSSÃO}

As quantidades de produto obtido e de material aderido na parede da câmara de secagem são aspectos fundamentais para a avaliação do rendimento de um processo de secagem por atomização. A distribuição de material seco para os testes com os seis aditivos utilizados pode ser verificada na Tabela 1 . Observa-se que, mesmo que por motivos operacionais as vazões de alimentação não tenham sido iguais para todos os testes, os resultados obtidos com Aerosil se destacam em relação aos dos outros aditivos pela maior recuperação de produto, menor retenção de material na parede da câmara de secagem e menor perda de produto no equipamento. 
Com relação à diferença de cor, os resultados para $\Delta E^{*}$ e para $\Delta b^{*}$ - o eixo amarelo-azul — são mostrados na Tabela 1. A menor diferença de cor em relação ao padrão ocorreu para a situação em que o aditivo foi o próprio leite em pó desnatado Molico; a segunda com o aditivo EMCAP e terceira com o Aerosil, sendo a diferença entre ambos muito pequena. $\mathrm{O}$ fato de os aditivos, exceto o leite em pó desnatado, serem pós brancos fez com que os produtos em geral apresentassem uma intensidade para a cor amarela inferior à do padrão adotado e, nesse caso, o pó obtido com o auxílio de Aerosil apresentou-se como o mais esbranquiçado de todos $\left(\Delta b^{*}\right.$ negativo). É interessante notar que o pó obtido sem uso de aditivos apresentou a maior discrepância de cor.

Tabela 1 - Resultados para o estudo da influência de aditivos na secagem de iogurte

\begin{tabular}{lccccccc}
\hline Parâmetros & $\begin{array}{c}\text { Iogurte } \\
\text { puro }\end{array}$ & DE 05 & DE 10 & EMCAP & $\begin{array}{c}\text { Goma } \\
\text { acácia }\end{array}$ & Molico & Aerosil \\
\hline Recuperação de MS (\%) & 39,1 & 48,7 & 49,8 & 39,2 & 17,7 & 25,2 & 76,0 \\
Retenção de MS (\%) & 40,1 & 26,7 & 30,6 & 22,1 & 15,0 & 44,8 & 14,4 \\
Perda de MS (\%) & 20,8 & 24,6 & 19,7 & 38,7 & 67,3 & 30,0 & 9,7 \\
$\Delta E^{*}$ & 10,2 & 4,4 & 3,0 & 2,7 & 6,6 & 2,1 & 2,8 \\
$\Delta b^{*}$ & 7,2 & 0,4 & $-1,3$ & $-1,8$ & 2,8 & $-1,9$ & $-2,6$ \\
\hline
\end{tabular}

Nota: O Aerosil foi utilizado na concentração de $3 \%$ no estudo dos aditivos.

A fluidez de um pó normalmente é caracterizada pelo ângulo de repouso do material, mas não exclusivamente. Com relação à maior ou menor fluidez, os pós são classificados em escoamento livre, semilivre e coesivo. Os pós de livre escoamento apresentam pouca ou nenhuma aglomeração entre suas partículas, enquanto que os de escoamento semilivre já apresentam partículas aglomeradas em maior quantidade (Walton e Mumford, 1999). Com relação à fluidez do pó se observou comportamento drasticamente diferente com o uso do Aerosil, que produziu um pó de livre escoamento, enquanto que as outras amostras apresentaram escoamento semilivre. A modificação da fluidez pelo Aerosil pode explicar a menor perda de material no equipamento e baixa retenção de material na câmara de secagem.

Comparando os resultados obtidos entre os seis aditivos estudados, a sílica pirogênica Aerosil foi escolhida para a segunda fase do estudo. A Tabela 2 apresenta os resultados da segunda parte do estudo, relativos à influência do teor de aditivo no desempenho da secagem, na qual é possível observar que a máxima recuperação e a menor quantidade de material aderido na parede foram obtidos com concentrações de Aerosil da ordem de 3\%.

Com relação à cor, na Tabela 2 observa-se que pelo fato de a cor do Aerosil ser branco ele exerce um efeito de esmaecimento da cor amarela à medida que sua concentração aumenta no produto, estando a tonalidade amarela do padrão situada na região compreendida entre as concentrações de 2 e 3\% de Aerosil. Já a menor diferença de cor em relação ao padrão ocorre com 3\% de Aerosil. De qualquer maneira, a observação da Tabela 2 permite inferir que a cor ideal do produto encontra-se certamente entre os teores de 2 e $4 \%$ de Aerosil. 
Tabela 2 - Resultados para o estudo da influência de Aerosil na secagem de iogurte

\begin{tabular}{lcccccc}
\hline \multirow{2}{*}{ Parâmetros } & \multicolumn{6}{c}{ Concentração de aditivo (\%) } \\
& 0,0 & 1,0 & 2,0 & 3,0 & 4,0 & 5,0 \\
\hline Recuperação de MS (\%) & 39,1 & 34,6 & 55,6 & 76,0 & 77,0 & 75,0 \\
Retenção de MS na câmara (\%) & 40,1 & 33,4 & 21,2 & 14,4 & 21,7 & 24,5 \\
Perda de MS no equipamento (\%) & 20,8 & 32,0 & 23,1 & 9,7 & 1,3 & 0,5 \\
$\Delta E^{*}$ & 10,17 & 5,56 & 6,37 & 2,78 & 6,28 & 8,53 \\
$\Delta b^{*}$ & 7,20 & 3,76 & 4,65 & $-2,64$ & $-6,09$ & $-8,22$ \\
\hline
\end{tabular}

Contudo, como pode ser apreciado na Figura 1, o aumento da concentração de Aerosil, de zero até 3\% na distribuição de partículas é responsável por uma drástica redução do tamanho das partículas maiores, o que pode ser inferido da curva de $D[v, 0,9]$, indicando que na concentração de $3 \%$ esse efeito parece ser máximo. Semelhante comportamento, porém não com a mesma intensidade, é observado nas curvas de $D[v, 0,5]$ e $D[v, 0,1]$. Assim, o aumento da fluidez do pó pode ser atribuída, em grande parte, à redução do diâmetro, das partículas. O span da distribuição acompanha com muita proximidade a curva de $D[v, 0,9]$, mostrando que a redução da dispersão no diâmetro das partículas dependeu basicamente da diminuição da quantidade de partículas de maior volume. A influência do aditivo também pode ser observada no comportamento do diâmetro de Sauter que, em concentrações de zero até $2 \%$ mantém-se próximo à curva de $D[v, 0,5]$ e para as concentrações de 3 a $5 \%$, aproxima-se da curva de $D[v, 0,1]$, indicando uma redução no diâmetro da partícula representativa da amostra.

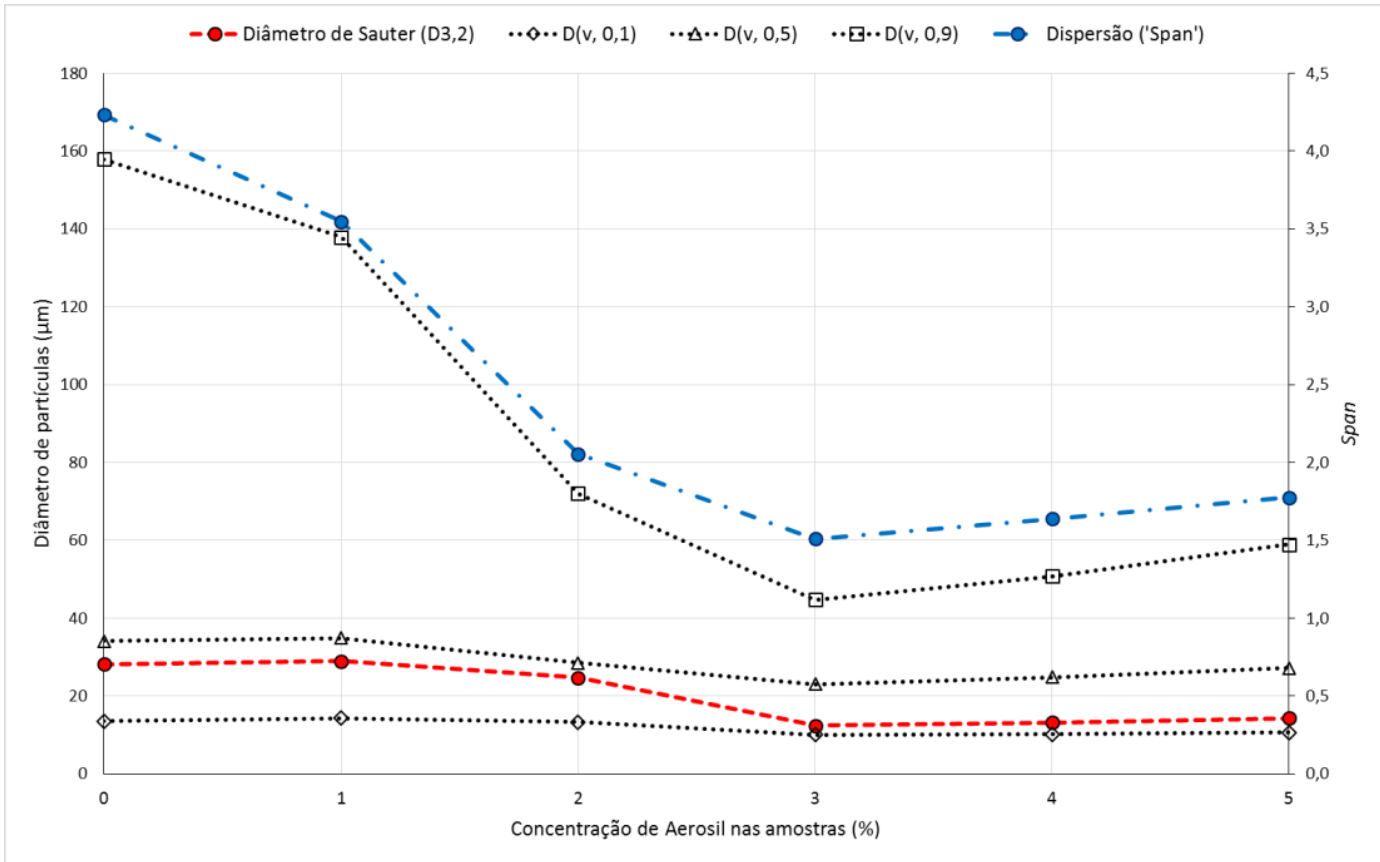

Figura 1 - Diâmetro de partículas e dispersão - span - da distribuição.

A análise das imagens de microscopia eletrônica de varredura (MEV) na Figura 2 explica que mais do que atuar diretamente no diâmetro individual das partículas formadas, o Aerosil atuou como um agente dispersante em aglomerados de partículas e a mudança de aspecto é 
evidente para o teor de $3 \%$, uma vez que nas partículas formadas com a adição de $2 \%$ de Aerosil ainda é possível identificar o aspecto das partículas de iogurte puro. Dessa forma, percebe-se que o Aerosil atua diminuindo a coesão entre as partículas por causa de sua afinidade pelas moléculas de água e também como uma barreira física entre as partículas. Além disso, com a baixa umidade no produto final, as temperaturas de transição vítrea dos componentes elevamse para valores próximos àqueles dos componentes secos, uma vez que o efeito de plasticização exercido pela água diminui, consequentemente, elevando a temperatura de transição vítrea da mistura dos componentes.

Por fim, o trabalho de Koc et al. (2010) que teve como propósito otimizar as condições do processo de secagem de iogurte natural em um atomizador de bico, as partículas analisadas por MEV mostraram-se em sua maioria esféricas, com a superfície fundamentalmente lisa, com depressões e fissuras eventuais, semelhante ao iogurte puro mostrado na Figura 2.

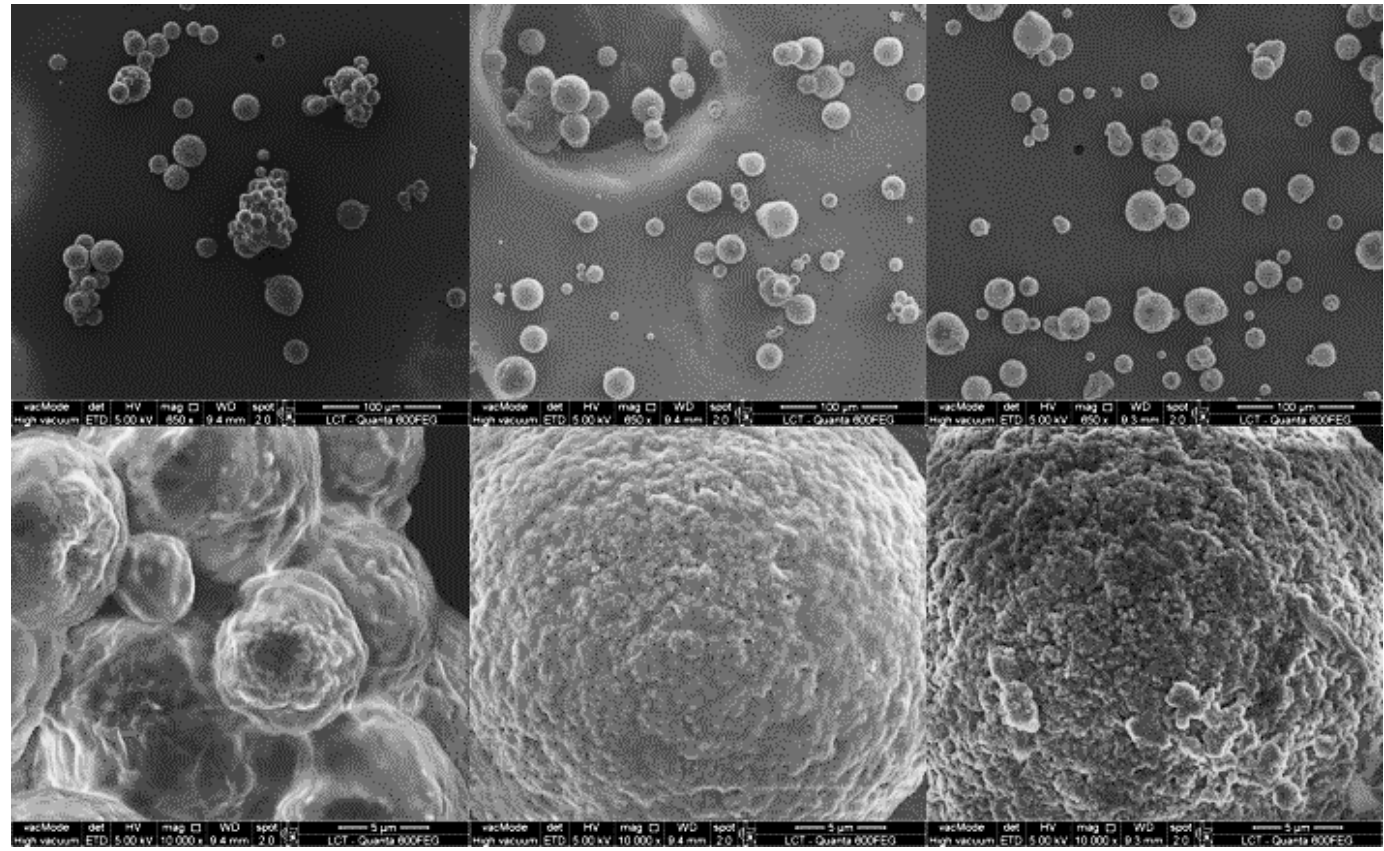

Figura 2 - Microscopia eletrônica de varredura (MEV) para amostras de iogurte puro (esquerda), com 2\% de Aerosil (centro) e 3\% de Aerosil (direita), para aumentos de $650 \times$ (superior) e $10000 \times$ (inferior).

\section{CONCLUSÕES}

O estudo mostrou que, dentre os aditivos utilizados como auxiliares de secagem de iogurte por atomização, o Aerosil, utilizado em concentrações entre 2 e $4 \%$, mostrou-se o mais promissor para a melhoria do processo, uma vez que com seu uso se obteve a maior recuperação de produto, a menor retenção de material na parede da câmara de secagem e a menor perda de produto do equipamento, além da cor mais próxima daquela do padrão escolhido. Por causa da ação dispersante do aditivo em aglomerados de partículas foi obtido um pó de livre escoamento e com um span da ordem de 1,5, o que indica uma boa homogeneidade para a distribuição de partículas do produto. 


\section{REFERÊNCIAS}

BARBOSA-CÁNOVAS, G. V. et al. Food Powders: physical properties, processing and functionality. New York: Kluwer, 2005. Cap. 12.

FIESP-ITAL. Brasil Food Trends 2020. Federação das Indústrias do Estado de São Paulo; Instituto de Tecnologia de Alimentos. São Paulo. 2010. 173 p.

FILKOVÁ, I.; HUANG, L.X.; MUJUMDAR, A.S. Industrial spray drying systems. In: MUJUMDAR, A. S. Handbook of Industrial Drying. 3. ed. Boca Raton: CRC, 2006. Cap. 10, p.215-56.

FU, N.; CHEN, X.D. Towards a maximal cell survival in convective thermal drying processes. Food Res. Int., v.44, p.1127-49, 2011.

GOULA, A. M.; ADAMOPOULOS, K. G. Effect of maltodextrin addition during spray drying of tomato pulp in dehumidified air: drying kinetics and product recovery. Drying Technol., v. 26, n. 6, p. 714-25, May 2008.

KEARNEY, N. et al. Development of a spray dried probiotic yoghurt containing Lactobacillus paracasei NFBC 338. Int. Dairy J., v. 19, p. 684-9, 2009.

KOC, B. et al. Spray drying of yogurt: optimization of process conditions for improving viability and other attributes. Drying Technol., v.28, p.495-507, 2010.

KUMAR, P.; MISHRA, H.N. Yoghurt powder - a review of process technology, storage and utilization. Food Bioprod. Process., v.82(C2), p.133-42, Jun. 2004.

LANGRISH, T.A.G.; CHAN, W.C.; KOTA, K. Comparison of maltodextrin and skim milk wall deposition rates in a pilot-scale spray dryer. Powder Technol., v.179, p.84-9, 2007.

MESTE, M.L. et al. Glass transition and food technology: a critical appraisal. J. Food Sci., v.67, n.7, p.2444-58, 2002.

PEIGHAMBARDOUST, S.H.; TAFTI, A.G.; HESARI, J. Application of spray drying for preservation of lactic acid starter cultures: a review. Trends in Food Sci. Technol., 2011. doi:10.1016/j.tifs.2011.01.009, article in press.

PEREIRA, O.W.; PETROVICK, P.R. Secagem por aspersão (spay drying) de extratos vegetais: bases e aplicações. Braz. J. Phamacogn., v.20, n.4, p.641-50, ago./set. 2010.

QUEK, S. Y.; CHOK, N. K.; SWEDLUND, P. The physicochemical properties of spray-dried watermelon powders. Chem. Eng. Process., v. 46, p. 386-392, 2007.

TRIBOLI, E.P.D.R.; GUT, J.A.W. Study of Spray Dried Yoghurt Production in A Pilot Scale Equipment. Online Proceedings of the 2013 AIChE Annual Meeting. San Francisco, EUA: AIChE. 2013.

TURCHIULI, C. et al. Evolution of particle properties during spray drying in relation with stickiness and agglomeration control. Powder Technol., v. 208, p. 433-40, 2011.

WALTON, D.E.; MUMFORD, C.J. Spray dried products - characterization of particle morphology. Trans IChemE, v.77A, p.21-38, Jan. 1999.

WOO, M. W. et al. Optimization of spray drying operating parameters - a quick trial-and-error method. Drying Technol., v. 25, p. 1741-47, 2007. 